\title{
Climatological Features of Cutoff Low Systems in the Northern Hemisphere
}

\author{
Raquel Nieto, Luis Gimeno, and Laura de la Torre \\ Universidad de Vigo, Facultad de Ciencias de Ourense, Ourense, Spain \\ Pedro Ribera and David Gallego \\ Departamento de CC Ambientales, Universidad Pablo de Olavide de Sevilla, Sevilla, Spain \\ RicARDo GARCÍA-HERRERA \\ Departamento de Fisica de la Tierra, Astronomía y Astrofísica, Universidad Complutense de Madrid, Facultad de Fisicas, Ciudad \\ Universitaria, Madrid, Spain \\ José Agustín García And Marcelino NuÑEZ \\ Departamento de Física, Universidad de Extremadura, Badajoz, Spain \\ Angel Redaño And Jerónimo LoRente \\ Departamento de Astronomía y Meteorología, Universidad de Barcelona, Barcelona, Spain
}

(Manuscript received 28 April 2004, in final form 9 September 2004)

\begin{abstract}
This study presents the first multidecadal climatology of cutoff low systems in the Northern Hemisphere. The climatology was constructed by using $41 \mathrm{yr}$ (1958-98) of NCEP-NCAR reanalysis data and identifying cutoff lows by means of an objective method based on imposing the three main physical characteristics of the conceptual model of cutoff low (the 200-hPa geopotential minimum, cutoff circulation, and the specific structure of both equivalent thickness and thermal front parameter fields).

Several results were confirmed and climatologically validated: 1 ) the existence of three preferred areas of cutoff low occurrence (the first one extends through southern Europe and the eastern Atlantic coast, the second one is the eastern North Pacific, and the third one is the northern China-Siberian region extending to the northwestern Pacific coast; the European area is the most favored region); 2) the known seasonal cycle, with cutoff lows forming much more frequently in summer than in winter; 3 ) the short lifetime of cutoff lows, most cutoff lows lasted 2-3 days and very few lasted more than 5 days; and 4) the mobility of the system, with few cutoff lows being stationary. Furthermore, the long study period has made it possible (i) to find a bimodal distribution in the geographical density of cutoff lows for the European sector in all the seasons (with the exception of winter), a summer displacement to the ocean in the American region, and a summer extension to the continent in the Asian region, and (ii) to detect northward and westward motion especially in the transitions from the second to third day of occurrence and from the third to fourth day of occurrence.

The long-term cutoff low database built in this study is appropriate to study the interannual variability of cutoff low occurrence and the links between cutoff lows and jet stream systems, blocking, or major modes of climate variability as well as the global importance of cutoff low in the stratosphere-troposphere exchange mechanism, which will be the focus of a subsequent paper.
\end{abstract}

Corresponding author address: Dr. Luis Gimeno, Universidad de Vigo, Facultad de Ciencias de Ourense, Ourense 32004, Spain. E-mail: 1.gimeno@uvigo.es 


\section{Introduction}

Cutoff low pressure systems are usually closed circulations in the middle and upper troposphere developed from a deep trough in the westerlies (Palmén and Newton 1969; Winkler et al. 2000). In isobaric maps (absolute topography maps), cutoff lows are easily recognized as close geopotential contours with a cold core. This is due to the fact that the air within the low has its origin at a higher latitude. Its intensity is higher in the upper troposphere, decreasing downward and being even possible to find anticyclonic circulation at surface. As a general rule, the troposphere below cutoff lows is unstable and convective severe events can occur, depending on surface conditions. Cutoff lows are associated with many substantial forecasting problems, mainly due to the different characteristics of the terrain and to the presence/absence of a warm ocean that permits/inhibits convection. Thus, the precipitation distribution associated with cutoff lows is a challenge to predict, especially when the precipitation is due to convection over a warm sea. Cutoff lows can bring moderate to heavy rainfall over large areas. In particular, they are among the most important weather systems that affect southern Europe and northern Africa and are responsible for some of the most catastrophic weather events in terms of precipitation rate (García-Herrera et al. 2001). Furthermore, cutoff lows are also important mechanisms of stratosphere-troposphere exchange (STE)(Bamber et al. 1984; Holton et al. 1995). In cutoff low systems, the tropopause is anomalously low, thus contributing to produce STE by convective or radiative erosion of the tropopause. There are also two other possible mechanisms of STE: turbulent mixing near the jet stream associated with the cutoff system and tropopause folding along the system (Hoskins et al. 1985; Price and Vaughan 1993; Wirth 1995). Although smaller in magnitude, the STE is similar to that produced by tropopause folding associated with upperlevel cyclogenesis. The STE associated with cutoff low systems is essential to explain anomalous values of tropospheric ozone in northern midlatitude areas (Oltmans et al. 1996; Gimeno et al. 1998) and in subtropical areas (Cuevas et al. 2000; Kentarchos et al. 2000).

There are previous climatological studies of cutoff low systems in the Northern Hemisphere but they use a very general algorithm to extract midtroposphere cyclones, though only a subset of them may be true cutoff lows (Bell and Bosart 1989; Parker et al. 1989; Novak et al. 2002), or they are limited to short periods (Price and Vaughan 1992, hereafter PV; Kentarchos and Davies 1998, hereafter KD), or they are limited to small areas such as the Mediterranean (Hernández 1999 and Cue- vas and Rodríguez 2002, hereafter HCR) or the northeast United States (Novak et al. 2002). They also differ in the way of identifying cutoff lows. Some of them use subjective analysis, which consists in analyzing visually daily $200-\mathrm{hPa}, 500-\mathrm{hPa}$, and surface charts (PV; KD), others use objective analysis with data on a pressure surface, mostly 500 or 200 hPa (Parker et al. 1989; Bell and Bosart 1989; Novak et al. 2002); whereas the rest use objective analysis but in terms of potential vorticity (Hernández 1999; Cuevas and Rodríguez 2002). Taking into consideration the previous studies for the whole Northern Hemisphere (PV for a 1-yr period, October 1982-September 1983; KD for the period 1990-94) it can be summarized that 1) cutoff lows are formed more often in summer than in winter; 2) there are favored regions of occurrence (Europe, China-Siberian region, the North Pacific, the northeast United States, the western part of the United States, and the northeast Atlantic), Europe being the most favored region (33\% of the total number); 3) cutoff lows are quasi stationary or their movement is erratic; 4) their duration is short; and 5) there is some interannual variability in the total number of cutoff lows (the maximum was 275 in 1994 and the minimum was 181 in 1991).

This work is part of a research project, Validación Climática de Modelos Conceptuales a Escala Sinóptica (VALIMOD), whose major objectives are 1) to validate climatologically the main extratropical synoptic conceptual models and 2) to study the compatibility of the studied extratropical synoptic patterns with quasistationary weather regimes, trying to connect weather and climate processes. Cutoff lows are the first synoptic pattern studied and the work has been divided into three main objectives. The first objective is to develop long-term comprehensive $\mathrm{NH}$ climatologies of cutoff lows for a 41-yr period (1958-98), using an approach based on imposing the three main physical characteristics of a cutoff low conceptual model. The second objective is to examine interannual variability in the climatological character of cutoff lows associated with the El Niño-Southern Oscillation (ENSO), the North Atlantic Oscillation (NAO), the Pacific-North Atlantic Oscillation (PNA), and the Northern Annual Mode (NAM), as well as trends in the number of cutoff lows and their relationship with blocking events and the jet stream position. The third objective is to check the expected weather events according to the conceptual model of the cutoff low in an area, such as the Iberian Peninsula, where precipitation due to cutoff lows is relevant. This paper presents the results obtained concerning the first objective, that is, the spatial distribution for the whole year is calculated (section 5) determining the main areas of occurrence. The seasonal 
cycle is examined in section 6. Statistical studies of duration and tracks of the cutoff lows are presented in section 7. The second and third objectives concerning cutoff low variability will be examined in a following paper.

\section{What is a cutoff low system?}

This discussion forms the basis of the conceptual model of cutoff lows. These systems are closed cyclonically circulating eddies isolated from the main western stream. These lows are upper and midtropospheric features and consequently they do not need to have a corresponding low in the lower levels of the troposphere. However, sometimes a cutoff low may start as an upper-level trough extending to the surface once it has developed. Air within cutoff lows is colder than in the surroundings, they are generally smaller than extratropical cyclones during its mature stage and they present a characteristic life cycle (Fig. 1). The typical process of the life cycle of a cutoff low can be separated into four stages. 1) The upper-level trough: The development of a cutoff low requires unstable potential waves within this layer of the troposphere. The temperature field is characterized by the temperature wave being situated behind the geopotential wave. Therefore substantial cold advection occurs within the area of the upper-level trough. During this stage of development, the field of the absolute topography is characterized by an increase of the amplitude of the geopotential wave and, sometimes, also by a decrease of the wavelength. The same development takes place for the temperature waves. 2) The tearoff: The increase in the amplitude of the waves continues, the trough deepens, and it starts to detach from the meridional stream. The cold air from the north streaming into southern regions is cut off from the general polar flow and the warm air from the south streaming into northern regions is cut off from the general subtropical flow. The consequence of this process is the development of a cold upper-level low within the southern part of the trough. 3) Cut off: The tie off is finished and the upper-level low is now much more pronounced. The wind field at $200 \mathrm{hPa}$ and sometimes at 500 and $1000 \mathrm{hPa}$ shows a well-developed closed circulation in the area of the former trough, which in the ideal case is cut off from the general meridional flow. 4) Final stage: The upper-level low usually merges with a large upper trough in the main zonal flow. Further details of meteorological properties of cutoff lows can be found in the meteorological literature describing case studies (e.g., Matsumoto et al. 1982; Hill and Browning 1987) or in more general studies about upper-level structures (e.g., Palmén and Newton 1969; Keyser and Shapiro 1986).

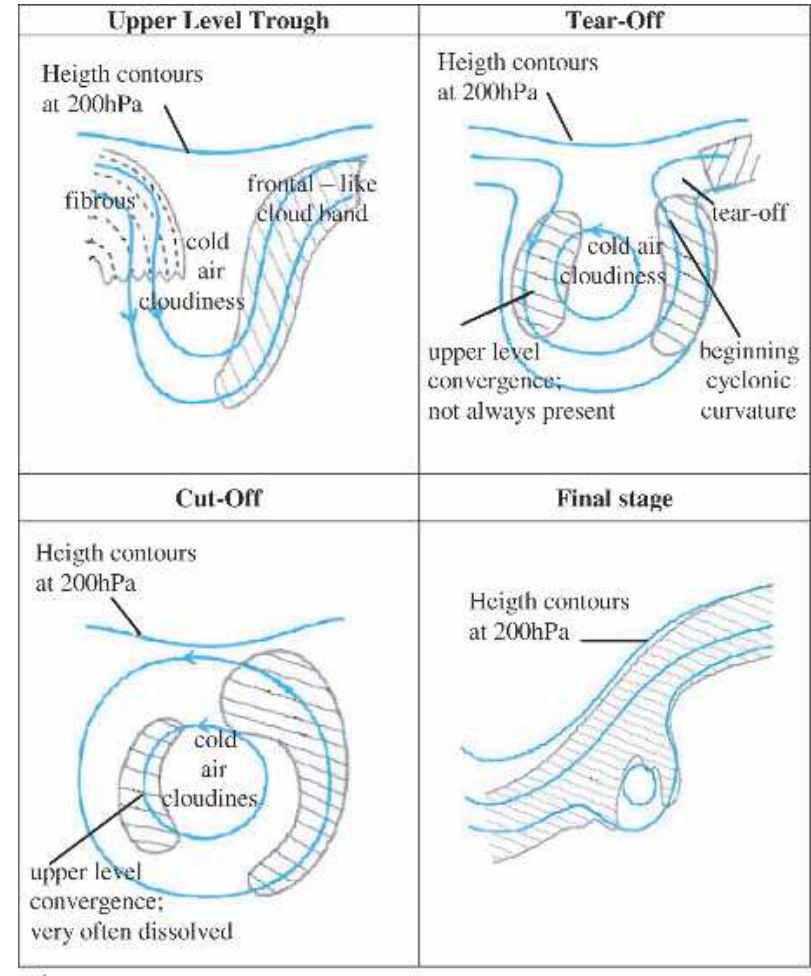

a)

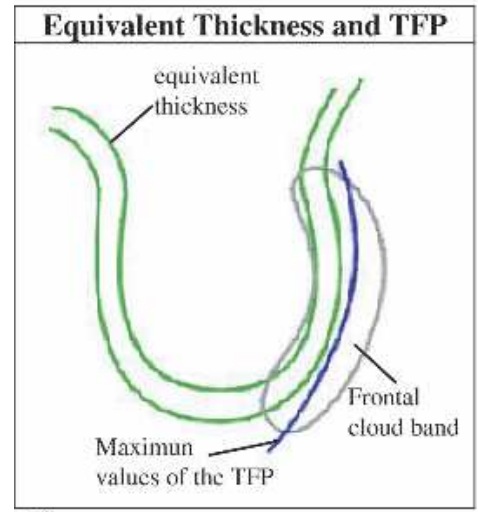

b)

FIG. 1. Diagram of the typical synoptic situation of a cutoff low showing (a) the different stages of its life cycle using the geopotential field and the satellite images (overlapped shaded areas) and (b) the equivalent thickness and TFP scheme at the tearoff phase.

These meteorological characteristics are represented by some physical parameters.

- Height contours at $200 \mathrm{hPa}$ : During the initial stage the absolute topography at $200 \mathrm{hPa}$ shows an upperlevel trough. During the different stages of development the trough forms an inverse omega shape that leads to a closed cyclonic circulation in the southern part of the trough. 
- Height contours at $1000 \mathrm{hPa}$ : Sometimes no distinct low-level features can be observed in this field. The gradient of the height contours is generally weak. Some weak cyclonic circulation may appear, initiated by the circulation from aloft, during the later phases of a cutoff.

- Equivalent thickness: This field is characterized by a thickness ridge in front of the low and a trough or a distinct minimum behind or in the center of the low.

- Thermal front parameter (TFP): There are two baroclinic zones, one in front of the low, which is connected with a frontal-like cloud band, and another one behind the low, connected with a baroclinic boundary.

- Temperature at $500 \mathrm{hPa}$ : The air within the cutoff low is colder than in the surroundings. The temperature field shows a life cycle similar to that of the upper height field.

\section{Data}

Data for 41 years (1958-98) from the National Centers for Environmental Prediction-National Center for Atmospheric Research (NCEP-NCAR) reanalysis were used (Kalnay et al. 1996) with a $2.5^{\circ}$ by $2.5^{\circ}$ resolution. For this study we use geopotential, zonal wind, and temperature daily data from 200, 300, and 1000 $\mathrm{hPa}$. Cutoff systems northward of $70^{\circ}$ or southward of $20^{\circ}$ were not included in the study. The reason of excluding systems northward of $70^{\circ}$ was to eliminate the main polar vortex from the statistics, whereas the small probability of occurrence is the reason to exclude cutoff lows southward of $20^{\circ}$.

\section{Diagnostic parameters}

The geopotential minimum characterizing a cutoff low system has been used as diagnostic parameter in previous climatologies based on objective analysis. So, Bell and Bosart (1989) and Novak et al. (2002) detected cutoff cyclones by evaluating each grid point at $500 \mathrm{hPa}$ and determining whether this grid point was a height minimum. For these authors a grid point is deemed a height minimum if it is the lowest height of the surrounding eight grid points; this minimum represents a cutoff low if there is a 30 geopotential meters (gpm) interval rise in all directions. When the identification of cutoff lows is based on subjective analysis, authors look for a closed cyclonic geopotential contour or any closed circulation in the wind vectors at a pressure level. This was the diagnostic parameter used by PV and KD, taking $200 \mathrm{hPa}$ as the pressure surface. Another diagnostic parameter is based on the fact that cutoff lows are char- acterized by an anomalously low tropopause that produces high values of potential vorticity. This characteristic has been used by HCR to identify cutoff lows. The criterion for detecting a cutoff low is the same in both studies, that is, a close contour of at least 2 potential vorticity units $\left(1 \mathrm{PVU}=10^{-6} \mathrm{~m}^{2} \mathrm{~s}^{-1} \mathrm{~K} \mathrm{~kg}^{-1}\right)$, with an inner maximum of at least 4 PVU.

Our analysis is based on an identification of cutoff lows by means of three consecutive steps based on physical characteristics of the conceptual model of cutoff lows described in section 2.

Step 1: Geopotential minimum and cutoff circulation at $200 \mathrm{hPa}$. In this step, two characteristics of cutoff lows were considered, the condition of a minimum of geopotential field at $200 \mathrm{hPa}$ and the isolation of the system from the westerlies general circulation in the upper troposphere. So, for every day, the grid points with height lower than that of at least six of the eight surrounding grid points were selected. Once this set was chosen, we retained those grid points where the geopotential difference with the surrounding points was at least $10 \mathrm{gpm}$. Then, only those points that fitted the condition of isolated cyclonic vortex were selected. To do that, a minimum of geopotential was considered a potential cutoff low point if there was a change in the direction of the 200-hPa zonal wind at any of the two adjacent grid points placed northward.

Step 2: Equivalent thickness. This parameter is the thickness of the atmospheric layer between two pressure surfaces. In a cutoff low, this field is characterized by a thickness ridge in front of the low. So, the equivalent thickness eastward of the central point must be higher than that at the central point. The typical field of equivalent thickness in a cutoff low is shown in Fig. 1 b. The pressure levels chosen to calculate this field were 200 and $300 \mathrm{hPa}$.

Step 3: Thermal front parameter. The mathematical definition of the TFP is

$$
\mathrm{TFP}=-\nabla|\nabla T| \cdot(\nabla T /|\nabla T|) .
$$

TPF is the change of temperature gradient in the direction of the temperature gradient. There is a clear relationship between the TFP as frontal analysis parameter and the well-known basic front definition, which fixes a cold front where temperature begins to fall and a warm front where the rise of temperature ends. The temperature used in the TFP can be taken from any level (200 $\mathrm{hPa}$ in our analysis). As described in section 2, cutoff lows have two baroclinic zones. One of these is placed in front of the low, which is connected with a frontallike cloud band. The typical field of the TPF in a cutoff low is shown in Fig. 1b. So, the grid point eastward of a 


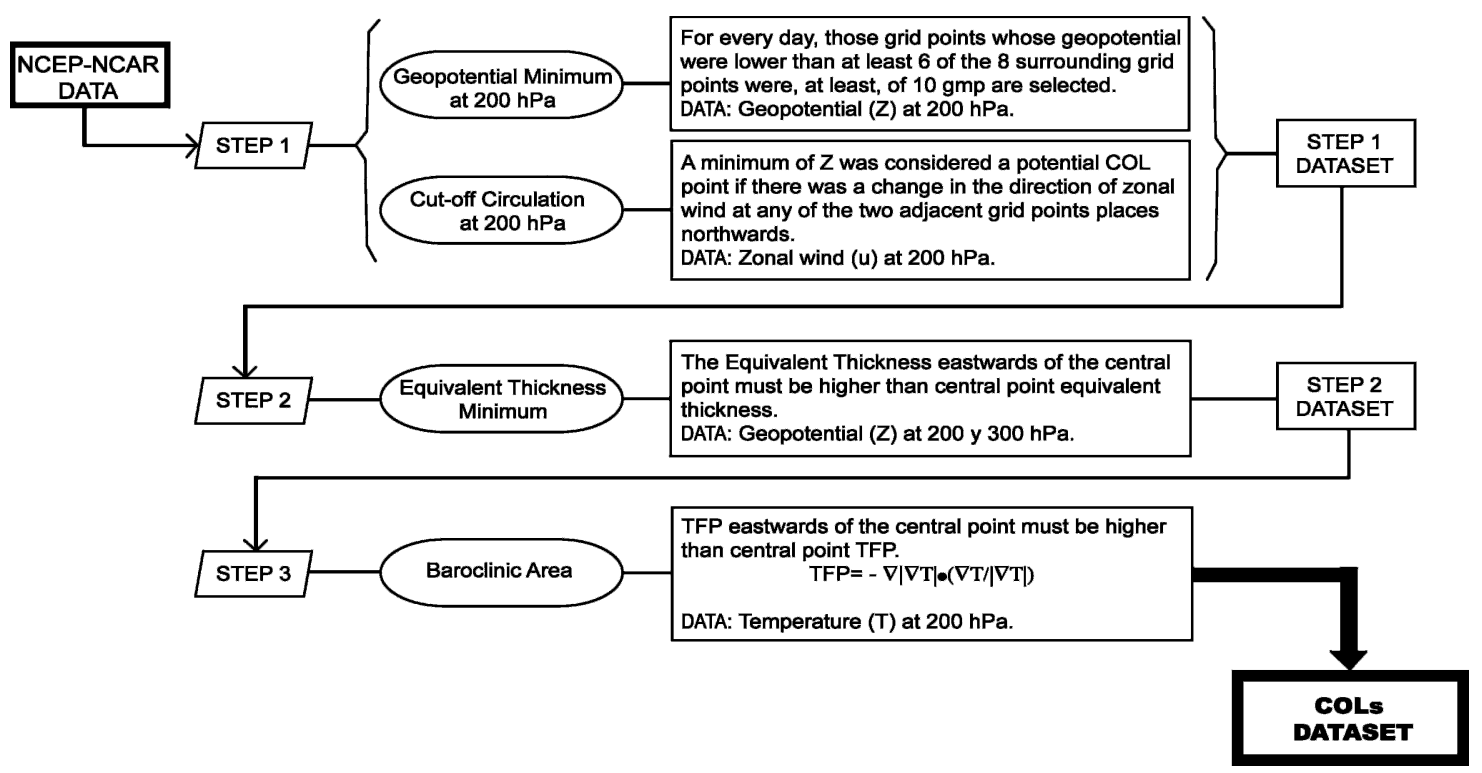

FIG. 2. Procedure used in the identification of cutoff lows.

cutoff low point must have TFP values higher than this to continue considering this point a cutoff low point.

Figure 2 summarizes the conditions imposed for every step and Figs. 3 and 4 illustrate the step-by-step procedure for a real case of a cutoff low. Our method identified a cutoff low starting 9 August 1991 and ending 11 August 1991 (Fig. 3). These are the three days when all our conditions are satisfied simultaneously. We have also displayed in Fig. 4 the day before (08 August) and the day after (12 August) that are not considered as cutoff low days because they do not fit all of the conditions. Although the condition of minimum geopotential was satisfied on both days, 8 August was not a cutoff low day because the other three conditions were satisfied, while on 12 August the condition relative to TFP was not satisfied.

For all the steps we also followed the following rules.

1) We considered that several grid points that fitted the criteria belonged to the same cutoff low when these points were adjacent.

2) We considered that a cutoff low was the same in two consecutive days when any of the grid points that fitted the cutoff low condition had, in the following day, at least one contiguous grid point fitting the condition.

3) Two systems were considered as independent cutoff lows when there were no contiguous grid points that fitted the condition.

4) When several adjacent points fitted these criteria on the same day, we used the northernmost and westernmost grid point as the representative position of the cutoff lows and this was the location used in the spatial analysis. This choice permits us to identify the closest point to the general circulation where the circulation is cut off.

Systems that lasted only one day were excluded from the analysis, using the same criteria of PV and KD. The number of cutoff lows decreases to about $30 \%$ from step 1 to step 3. So 7946 cutoff low candidates were identified in step 1, 3003 in step 2, and 2362 in step 3.

Our method to identify cutoff lows, although objective, is not entirely unambiguous. The problem of mistaking a system as a cutoff low is minimized by imposing three consecutive and restrictive conditions (systems after step 3), but there is a small probability of ignoring systems that in a subjective analysis, such as those used by PV or KD, would have been considered cutoff lows. Although a rigorous comparison between subjective methods used by $\mathrm{PV}$ and $\mathrm{KD}$ and our method is not possible because of the different data used and the clear difference in the length of the studied period, we can check our procedure of identification by comparing our results with these reached by PV and KD in their studies [April-September 1983 in PV and summer, June-August (JJA), in 1990 and 1991 in KD]. Figure 5 shows the distribution of cutoff lows between April and September 1983, the period analyzed in PV. In general terms we can see a good agreement in extratropical areas; PV overestimate cutoff lows in near-polar or polar regions (northward of $60^{\circ} \mathrm{N}$ ) and underestimate them in subtropical or even tropical areas. With more detail, northern Europe and southern 


\section{Conditions}

$\mathrm{Z}$ gpm $(200 \mathrm{hPa})$

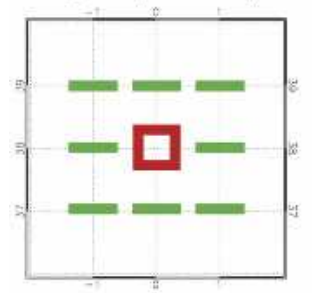

$\mathrm{U} \mathrm{m} / \mathrm{s}(200 \mathrm{hPa})$

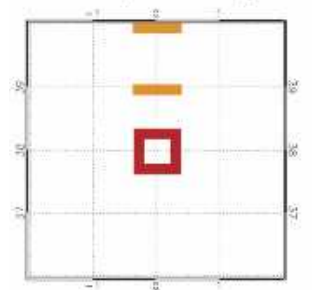

Equivalent Thickness gmp $(200-300 \mathrm{hPa})$

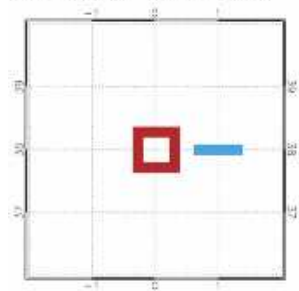

$\mathrm{TPF}^{*} \mathrm{e} 14 \mathrm{~K} / \mathrm{m} 2$

$(200 \mathrm{hPa})$

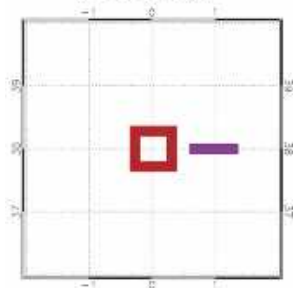

DAYS OF COL DETECTED IN OUR ANALYSIS

09-08-1991

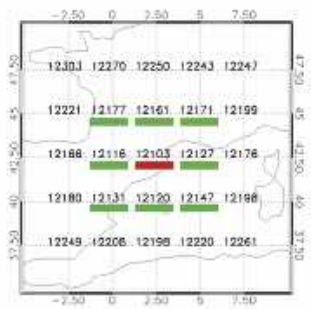

10-08-1991

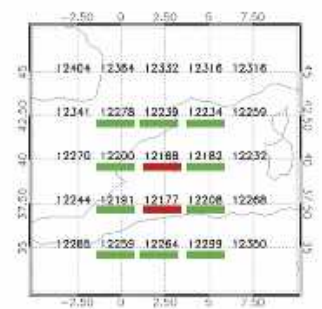

11-08-1991

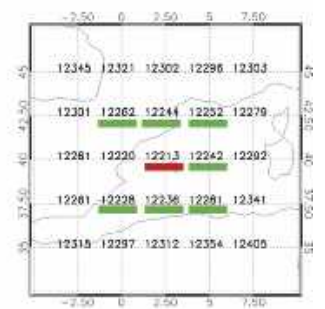

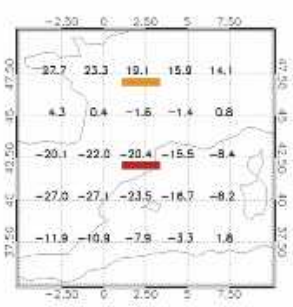
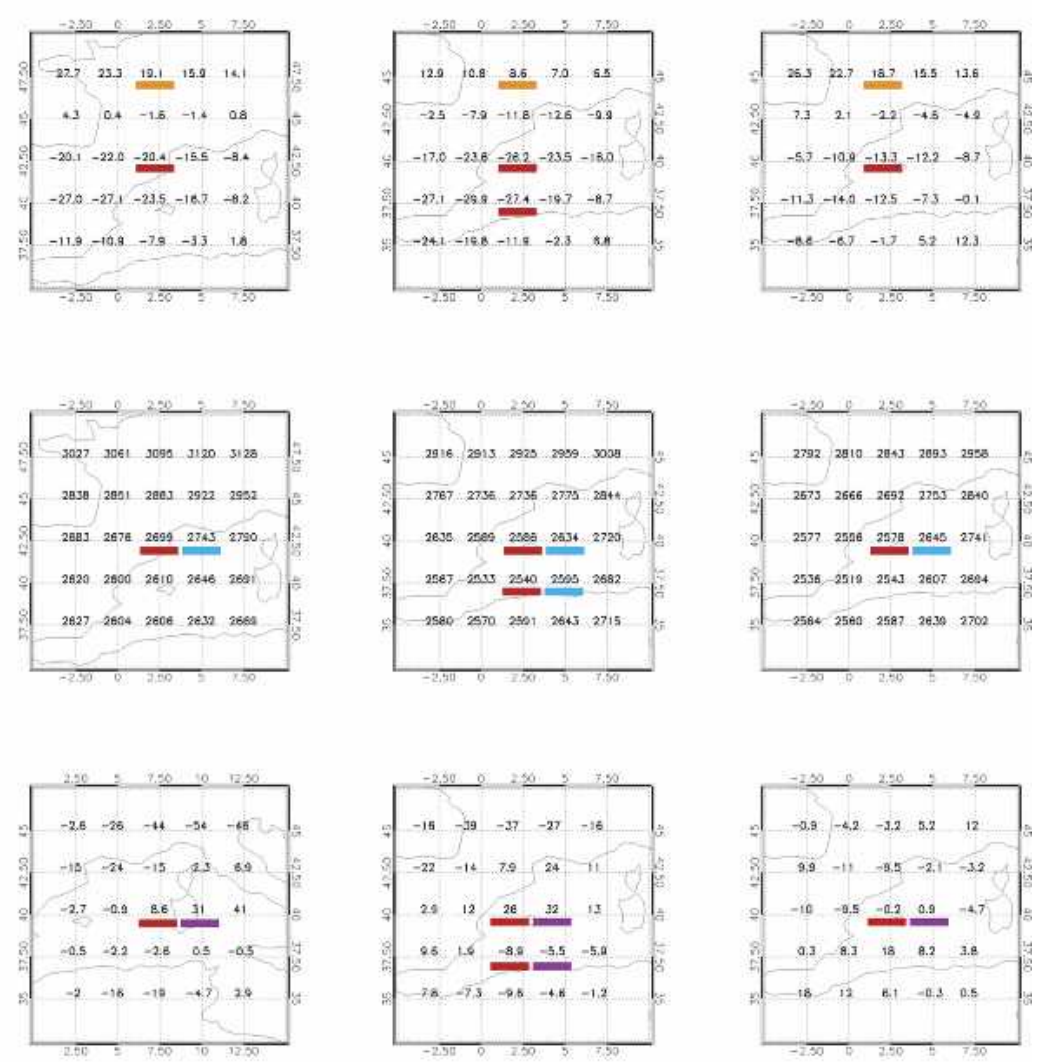

口: POINT of COL.

: at least 6 of these points have a geopotential higher than $10 \mathrm{gpm}$ with the point of COL.

- : zonal wind at these points have to be opposite sign of the zonal wind at the point of COL.

: this point must be higher than the point of $\mathrm{COL}$.

: this point must be higher than the point of COL.

FIG. 3. Step-by-step example of the automated method following a real case of cutoff low (9-11 Aug 1991) detected in our analysis.

North America are areas where our procedure does not detect cutoff lows, while both the central Pacific and central Atlantic are the areas where PV did not detect them. In any case, these regions are not the main areas of cutoff lows occurrence (southern Europe, the North American Pacific coast, and the Asian Pacific coast); for those areas the agreement between the two methods is good. The same comparison was done for 1990 (Fig. 6a) and 1991 (Fig. 6b) summers (defined as JJA; the two periods analyzed by KD with the higher number of cutoff lows (Figs. 5c, g in KD). The same general conclusions can be reached showing good agreement in 


\section{DAYS OF COL NO DETECTED IN OUR ANALYSIS}

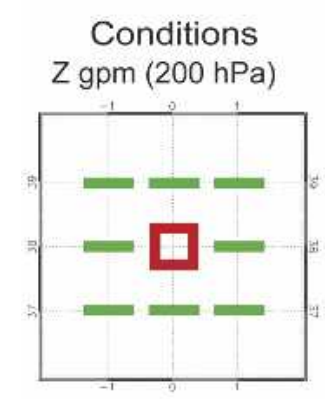

08-08-1991

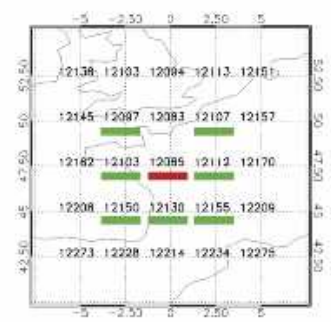

$\mathrm{U} \mathrm{m} / \mathrm{s}(200 \mathrm{hPa})$

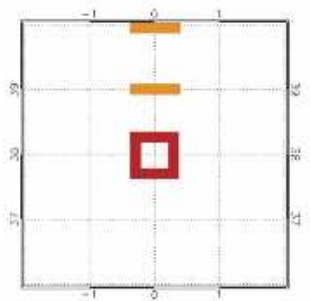

Equivalent Thickness $\operatorname{gmp}(200-300 \mathrm{hPa})$

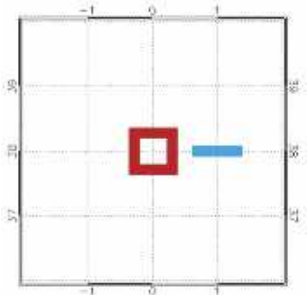

$\mathrm{TPF}^{*} \mathrm{e} 14 \mathrm{~K} / \mathrm{m} 2$ $(200 \mathrm{hPa})$
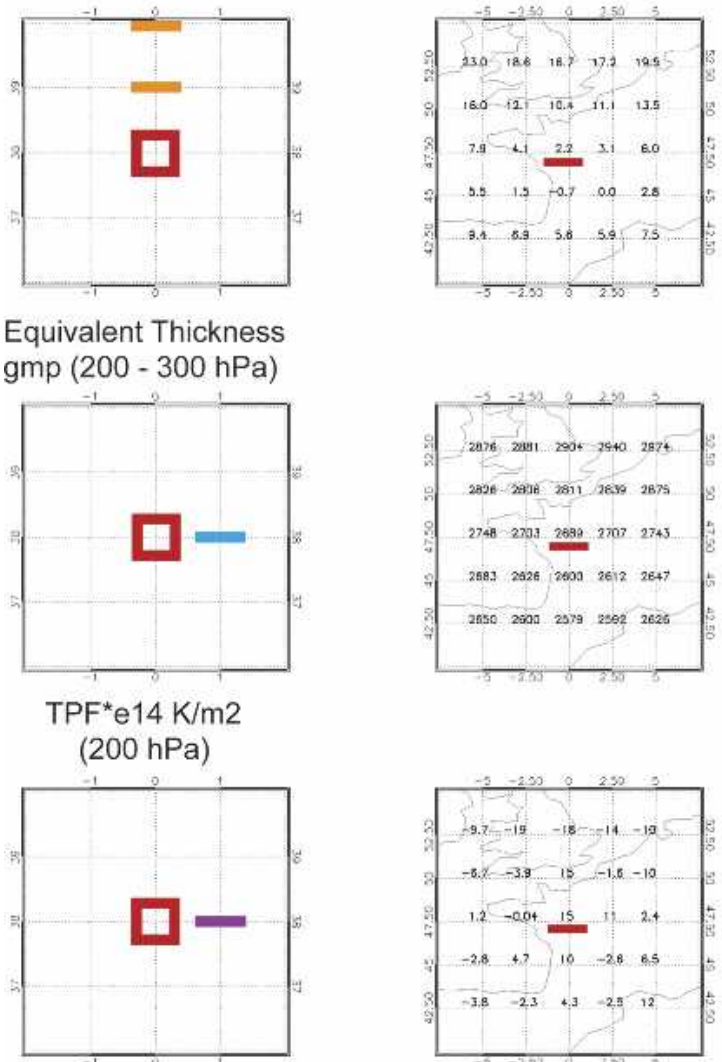

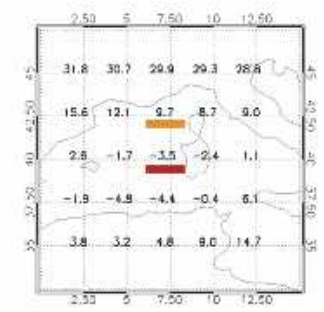

12-08-1991
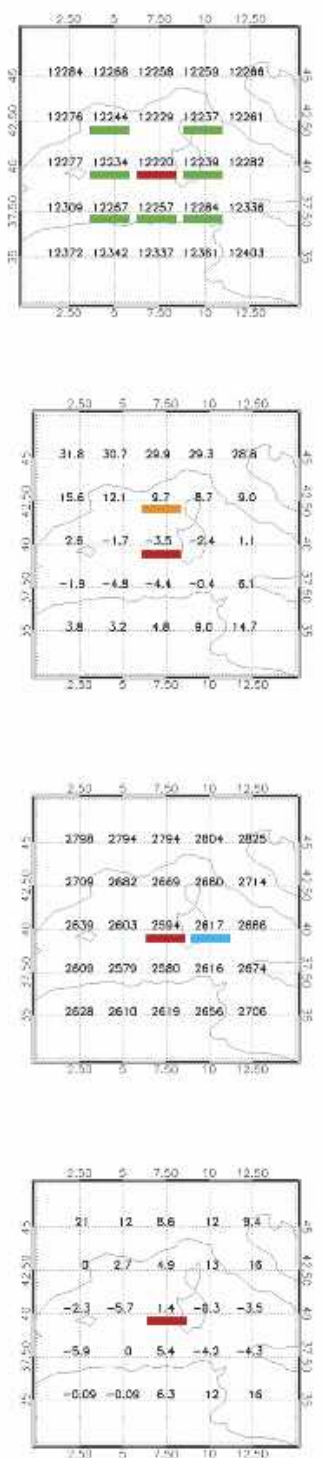

口: POINT of COL.

: at least 6 of these points have a geopotential higher than $10 \mathrm{gpm}$ with the point of COL.

$=$ : zonal wind at these points have to be opposite sign of the zonal wind at the point of COL.

: this point must be higher than the point of $\mathrm{COL}$.

: this point must be higher than the point of COL.

FIG. 4. As in Fig. 3, but for the day before the first day detected (8 Aug 1991) and the day after the last day detected (12 Aug 1991) by our method. These two days do not fulfill some of the imposed conditions.

extratropical latitudes, especially in the three main areas of cutoff low occurrence.

Another concern was to know if we identified real cutoff systems and not merely $200-\mathrm{hPa}$ cyclones. To check this, we focused in the sector from $25^{\circ}$ to $47.5^{\circ} \mathrm{N}$ latitude and from $50^{\circ} \mathrm{W}$ to $40^{\circ} \mathrm{E}$ longitude, which, in section 5 and thereafter, will be called the European sector. We compared the behavior of the zonal circulation in two regions as shown in Fig. 7: A: around the cutoff low point, representative of the cutoff low gen- 


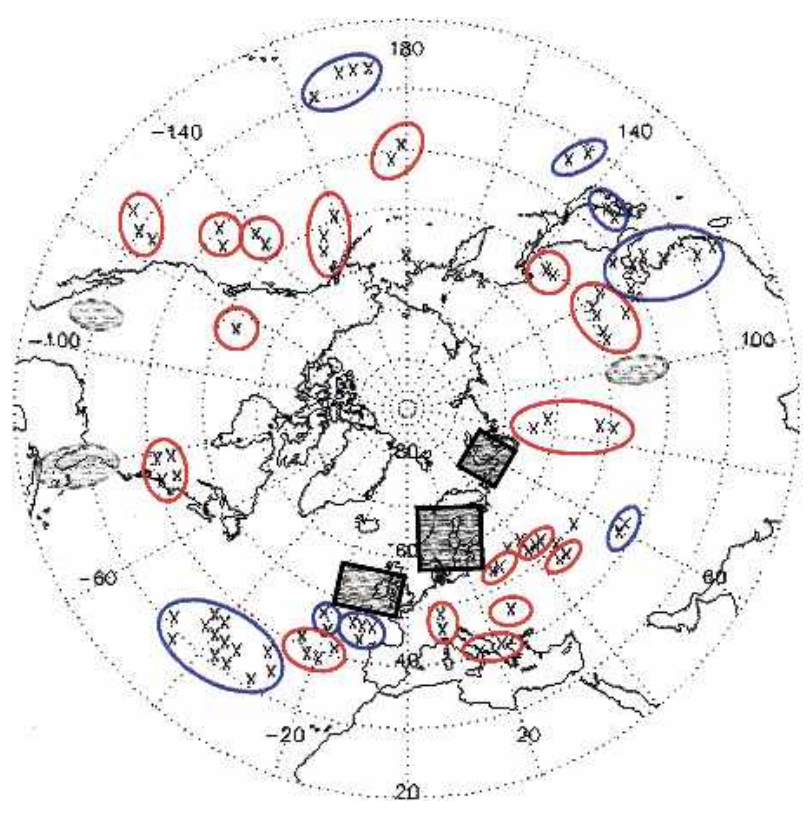

FIG. 5. Distribution of cutoff systems between Apr and Sep 1983, the period analyzed in PV. Crosses denote cutoff lows identified by means of our objective method (step 3). Crosses circled in red represent systems also identified in PV's study (Fig. 5 in Price and Vaughan 1992), crosses circled in blue are those systems that PV did not identify, circled areas in gray denote cutoff lows identified by PV but not in our analysis for step 3 (but identified in previous steps), and rectangles in gray means cutoff lows identified by PV but not in our analysis (in any of the steps).

eral circulation, and $\mathrm{B}$ : in the area just to the north, representative of the westerly circulation. The relationship between both behaviors for a real cutoff case should be very different from the climatological mean. In the extratropics, the general circulation is dominated by westerlies, so B and A are usually positive and similar. But in the case of a real cutoff, the easterlies associated with the cutoff low change the sign of A or, at least, diminish its value, while they do not affect $\mathrm{B}$ at all. Therefore, the ratio $\mathrm{B} / \mathrm{A}$ should have a negative or a very high value for a real cutoff low. Here A was computed by averaging the zonal wind for the point of cutoff low and its eight adjacent grid points (blue box in Fig. 7, top panel) and B is the average for the nine grid points just north (green box in Fig. 7 top panel). Here $\mathrm{Am}$ and $\mathrm{Bm}$ are the climatological means for the calendar day of the cutoff low in all of the period. Thus, $\mathrm{Bm}$ and Am should have the same sign and, therefore, $\mathrm{Bm} / \mathrm{Am}>0$. In the case of a cutoff we should have $\mathrm{B} / \mathrm{A}$ $<0$ or $\mathrm{B} / \mathrm{A} \gg \mathrm{Bm} / \mathrm{Am}$.

Both ratios were calculated for every cutoff low day and are represented in Fig. 7 (bottom panel). The mean of $\mathrm{B} / \mathrm{A}$ is negative $(-4.41)$ and the mean of $\mathrm{Bm} / \mathrm{Am}$
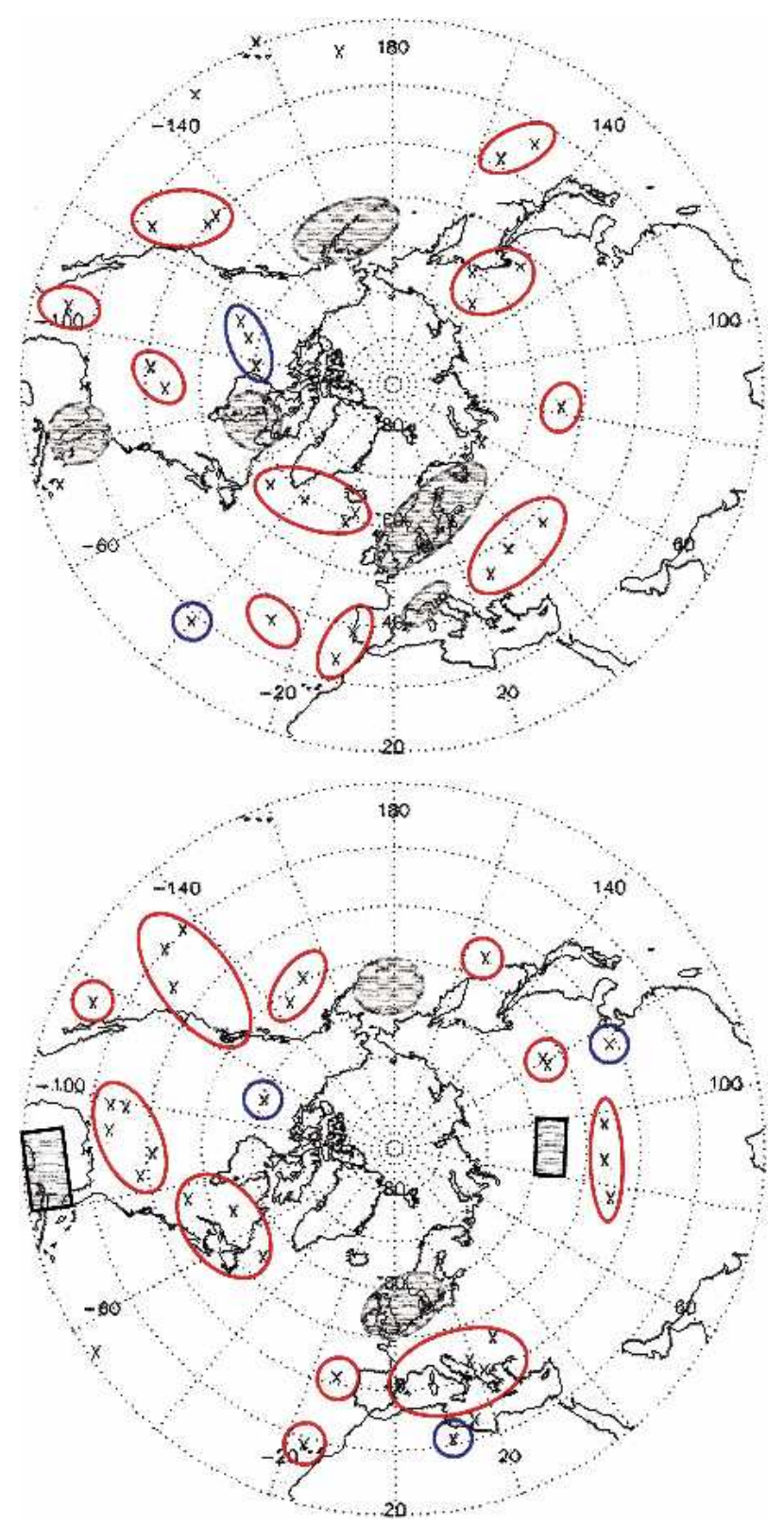

FIG. 6. As in Fig. 1, but for the summers of (a) 1990 and (b) 1991, i.e., the periods analyzed by KD with the higher number of cutoff lows (Figs. 5c,g in Kentarchos and Davies 1998).

positive (1.50). A Student's $t$ test shows that both series of $\mathrm{B} / \mathrm{A}$ and $\mathrm{Bm} / \mathrm{Am}$ for the 601 cases of cutoff lows are significantly different $(p=0.02)$. As expected, $\mathrm{Bm} / \mathrm{Am}$ was always positive because the box corresponds to latitudes with westerlies. However B/A was mainly negative, due to the usual negative value of $\mathrm{A}$. For these cases of a negative value of $\mathrm{B} / \mathrm{A}$ it is evident that the system was cut off from the general atmospheric circulation. There are few cases with positive values of B/A (same sign of zonal wind in the blue and the green box). 

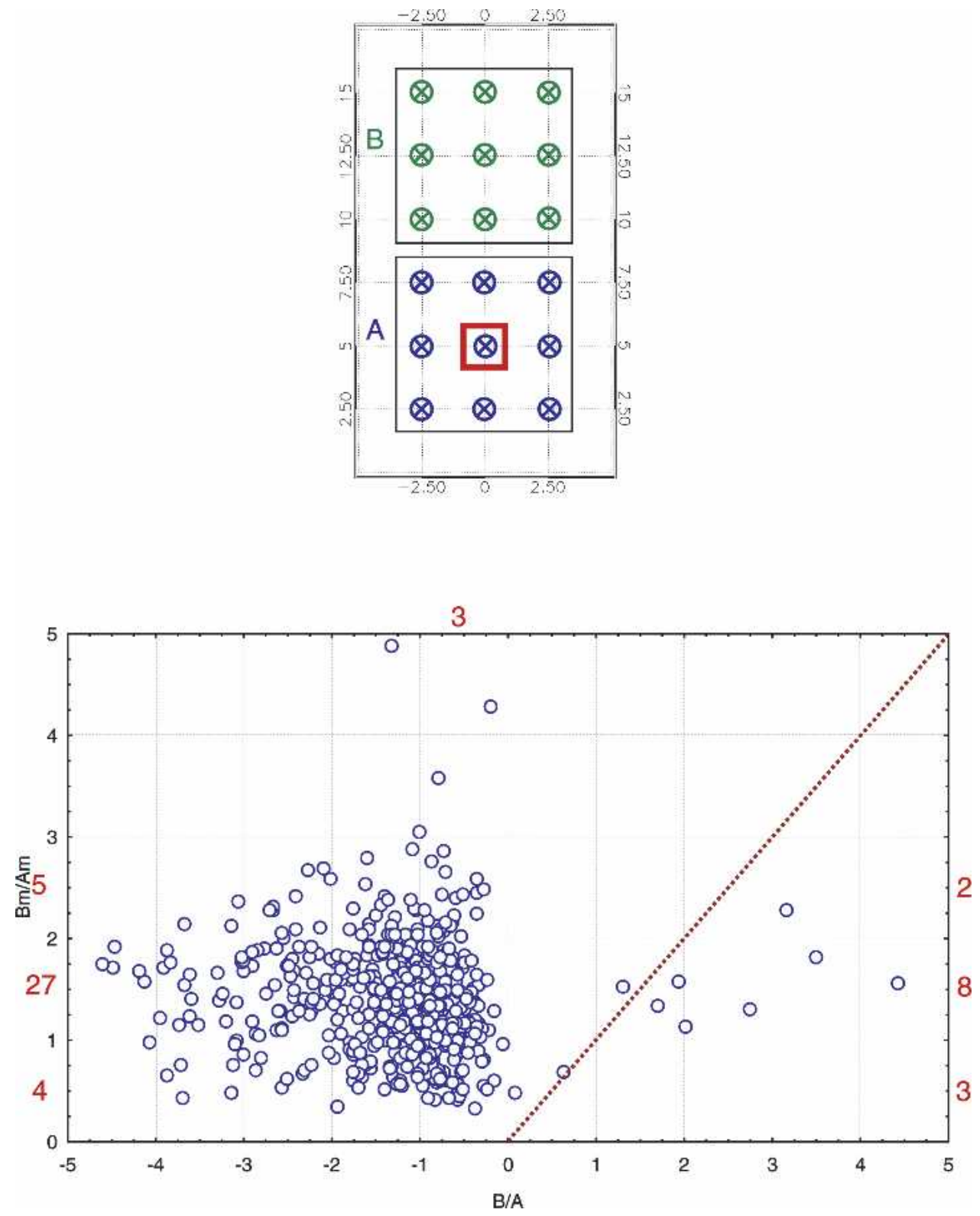

FIG. 7. Diagram of the method used to prove that cutoff lows are truly cut off from the westerly flow. (top) The schematic diagram used to calculate A and B. Blue box: points used to calculate the average of zonal wind in the surroundings of the representative point of cutoff low (red box). Green box: points used to calculate the average of zonal wind for the points farther north than the point of cutoff low. (bottom) Distribution diagram showing the relationship between $\mathrm{B} / \mathrm{A}$ and $\mathrm{Bm} / \mathrm{Am}(\mathrm{Bm}$ and $\mathrm{Am}$ are the climatological daily of averages B and A) during the period 1958-98 for every cutoff low. Numbers in red are cases out of the diagram limits. The red line indicates the same value of $\mathrm{B} / \mathrm{A}$ and $\mathrm{Bm} / \mathrm{Am}$.

They correspond mostly to both positive values of B and A. There are only 9 of 601 cutoff lows (less than $1.5 \%$ of the cases) with similar values of $\mathrm{B} / \mathrm{A}$ and $\mathrm{Bm} /$ Am. They correspond to those cases when circulation can be not cut off (close to the red line in Fig. 7, bottom panel). In the other 13 cases with positive values of $\mathrm{B} / \mathrm{A}$ the ratio is high enough to think that lows are truly cut off from the westerlies. These results show the reliability of our method when detecting cutoff lows (not only 200-hPa cyclones) with climatological purposes.

We also calculated the number of cutoff lows in which a surface low was formed during the cutoff low day or during the following day for this European sector. This occurs for 283 of the 601 identified systems, 


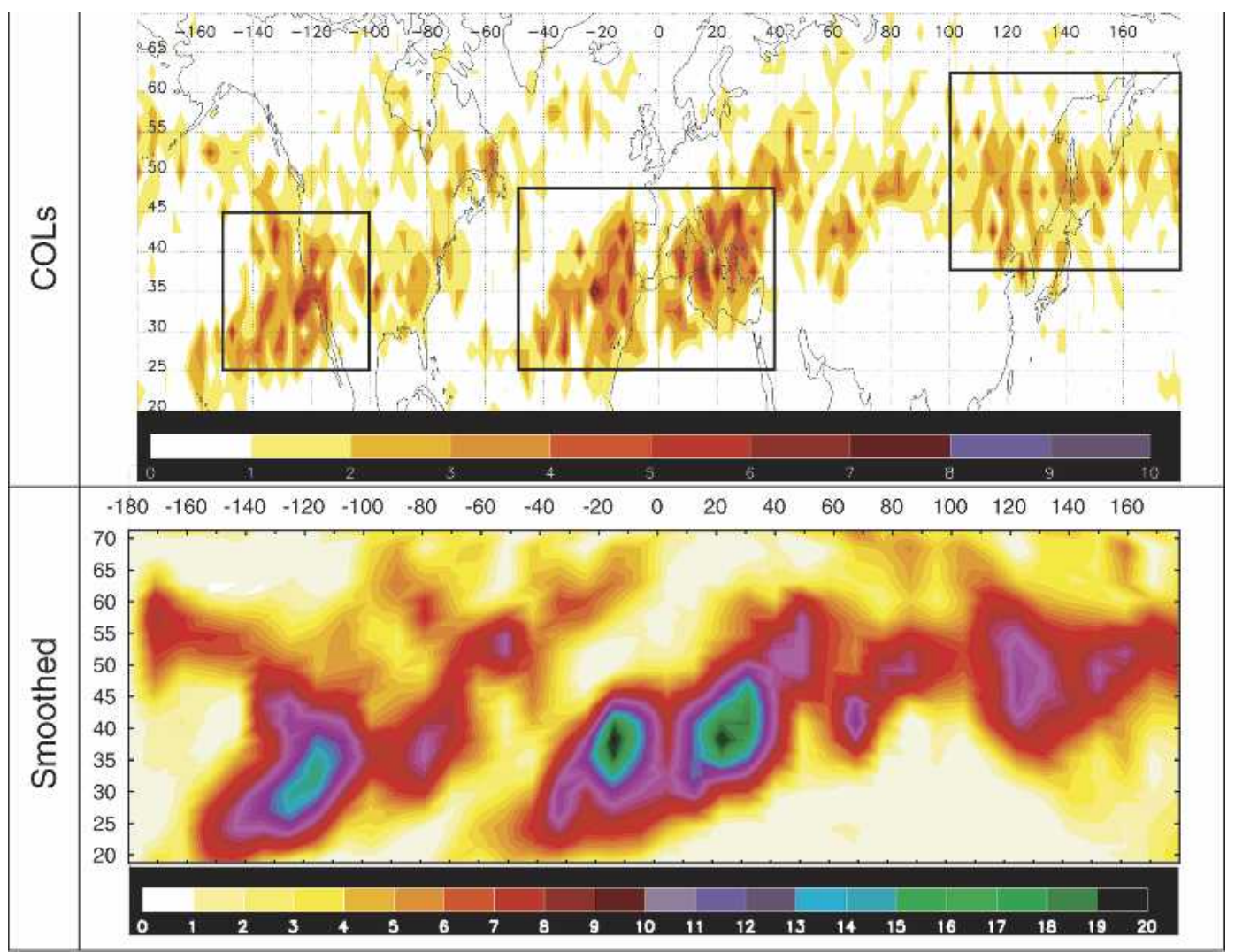

FIG. 8. (top) Total number of cutoff lows by grid point $\left(2.5^{\circ} \times 2.5^{\circ}\right)$ for the period $1958-98$ without splitting in seasons. (bottom) A smoothed version calculated for boxes of $5^{\circ}$ lat $\times 10^{\circ}$ lon.

representing $47.1 \%$ of the total cases of cutoff lows. We also checked if cutoff lows identified by our method correspond to regions with high values of potential vorticity. The criterion for doing this was to detect a close contour of at least $2 \mathrm{PVU}$ with an inner maximum of at least $4 \mathrm{PVU}$ at $330 \mathrm{~K}$ (similar to HCR). We took as a contour the eight grid points surrounding the potential vorticity value higher than 4 PVU. Results show that $72.63 \%$ of the cutoff lows identified by our method in the European sector correspond to potential vorticity maxima. Thus, this confirms the reliability of our method to detect cutoff low systems.

\section{Spatial distribution}

The location of cutoff lows changes from season to season. However, in both hemispheric climatologies ( $\mathrm{PV}$ and $\mathrm{KD}$ ) there are areas where cutoff lows are most likely to occur. These areas are western and central parts of Europe, the North China-Siberia region, the North Pacific and northeast Canada during winter, and southwestern Europe, northern Africa, northern Russia, the North Pacific (close to Alaska), the north and east of China, and the western and southern part of the United States during spring and summer.

Figure 8 shows the distribution of cutoff lows over the Northern Hemisphere for the entire period (195898) without splitting in seasons. Color scales refer to absolute number of cutoff lows, so only the first day of occurrence was counted. This display is significatively different from those used in KD or PV in their studies of spatial distribution, which showed the absolute number of days for which a cutoff low existed. The plot of the first day is more representative in the identification of areas of cutoff low occurrence, which is the objective of this section. Most of the cutoff lows are concentrated in three regions: 1) southern Europe and the eastern Atlantic coast, including the Mediterranean and northern Africa, hereafter called the European sector; 2) the eastern North Pacific coast and the northeastern United States, hereafter the American sector; and 3) the North China-Siberian region extending to the northwestern Pacific coast, hereafter the Asian sector. The three areas of higher occurrence are more evident in a smoothed version of the distribution of cutoff lows (bottom panel in Fig. 8) in which the number of cutoff 
lows was recalculated for boxes $5^{\circ}$ latitude $\times 10^{\circ}$ longitude. The three sectors can be more easily identified by latitude-longitude boxes, so the European sector extends from $25^{\circ}$ to $47.5^{\circ} \mathrm{N}, 50^{\circ} \mathrm{W}$ to $40^{\circ} \mathrm{E}$; the American sector from $25^{\circ}$ to $45^{\circ} \mathrm{N}, 100^{\circ}$ to $150^{\circ} \mathrm{W}$; and the Asian sector from $37.5^{\circ}$ to $62.5^{\circ} \mathrm{N}, 100^{\circ} \mathrm{E}$ to $180^{\circ}$. In general, these results are concordant with previous partial climatologies, although in KD and PV the area of most frequent occurrence extended to northern Europe and northeast Canada.

Figure 9 shows a more detailed picture of the geographical distribution of the absolute number of cutoff lows for the three main sectors of occurrence. Figures on the left display absolute number of cutoff lows computed for $2.5^{\circ} \times 2.5^{\circ}$ boxes, and figures on the right are smoothed versions in which the number of cutoff lows were recalculated for boxes of $5^{\circ}$ latitude $\times 10^{\circ}$ longitude. Inside the European sector, there are two areas that exhibit higher frequencies of cutoff low formation, the eastern Atlantic and the southern parts of the European continent-Mediterranean region. Both preferred areas were already identified in partial climatologies of cutoff lows (KD) and in an analysis of geographical distribution of "cold pools" over Europe (Llasat and Puigcerver 1990). However, the eastern area (from the Italian Peninsula to the Balkan Peninsula) is more clearly defined in our analysis. However, PV did not analyze cutoff low distribution over Europe with this detail, and the regional climatology based on maxima of potential vorticity (HCR) identified only a maximum close to the Iberian Peninsula. The two areas of higher occurrence in the American sector, at two different latitudes, can be caused by the seasonal cycle since the main production mechanism responsible for cutoff low formation (meridional displacement of jet streams) shows a seasonal cycle. In the Asian sector the most frequent occurrence area has a "band" shape between $42.5^{\circ}$ and $55^{\circ} \mathrm{N}$ with two local maxima placed at $115^{\circ}$ and $140^{\circ} \mathrm{E}$.

Studies using long reanalysis data can be affected by inhomogeneities in the observational data, in particular the introduction of the satellite data in 1979, which could result in jumps in climatological quantities with the introduction of new observing systems. To check if the inhomogeneities can affect the climatological quantities of cutoff lows, the period of analysis was divided into two periods (1958-78 and 1979-98) and the distribution of cutoff lows over the Northern Hemisphere for both periods were calculated (figure not shown). There are no clear differences from one period to the other with the similar three areas of higher cutoff low occurrence and with maxima and minima placed on similar positions.

\section{Temporal distribution}

Previous climatologies showed that cutoff low systems in the Northern Hemisphere are much more common in summer months, particularly in June and July. Price and Vaughan reported that $30 \%$ of cutoff lows during 1 October 1982-30 September 1983 occurred in June and July and KD found that $37 \%$ of the cutoff lows during the period 1990-94 formed in summer. The season with the least number of cutoff lows was clearly winter $(15 \%$ in KD for the whole season and 9\% in PV for December and January). The seasonal distribution of cutoff lows showed very similar patterns when it was divided into the three types of cutoff lows by PV and for cutoff lows below $40^{\circ} \mathrm{N}$ and between $40^{\circ}$ and $70^{\circ} \mathrm{N}$ in $\mathrm{KD}$.

Figure 10 shows the seasonal distribution of cutoff lows for the analyzed period 1958-98 and for each main sector of occurrence. We can see that the three sectors show the same type of seasonal distribution. Cutoff lows are much more common in the summer for the three regions, with $44.6 \%$ occurring during this season for the European sector, $49.5 \%$ for the American sector, and $58.4 \%$ for the Asian sector. During winter, far fewer cutoff lows formed in the three regions, only $10.6 \%, 3.5 \%$, and $5.6 \%$ for the European, American, and Asian sectors, respectively. A similar seasonal behavior found in previous partial climatologies (PV and KD) was attributed to the existence of weaker jet streams during summer, which allows greater meridional flow and more likelihood in the probability of cutoff low formation. To know if the inhomogeneities in the reanalysis data can affect the seasonal distribution of cutoff lows we studied the seasonal distribution in two periods (1958-78 and 1979-98), not finding significant differences.

To examine geographical differences in the seasonal distribution, we analyzed the number of cutoff lows for each season and main sector of occurrence (Fig. 11). Colored areas include at least $95 \%$ of the total number of cutoff lows for each sector and season. Numbers over colored areas denote places where more than one cutoff low is present in that period. There are substantial seasonal changes in the region of occurrence, so in the European sector most cutoff lows occurred in northern Africa and southern Europe during winter and extend toward higher latitudes during the rest of the year. The bipolar structure shown in section 5, consisting in a maximum over the Atlantic coast and another over the Adriatic Sea, appears in spring, summer, and fall, being more expanded during summer. Furthermore, the Atlantic pole is displaced to lower latitudes during fall. In the American sector, the area of occurrence is limited 


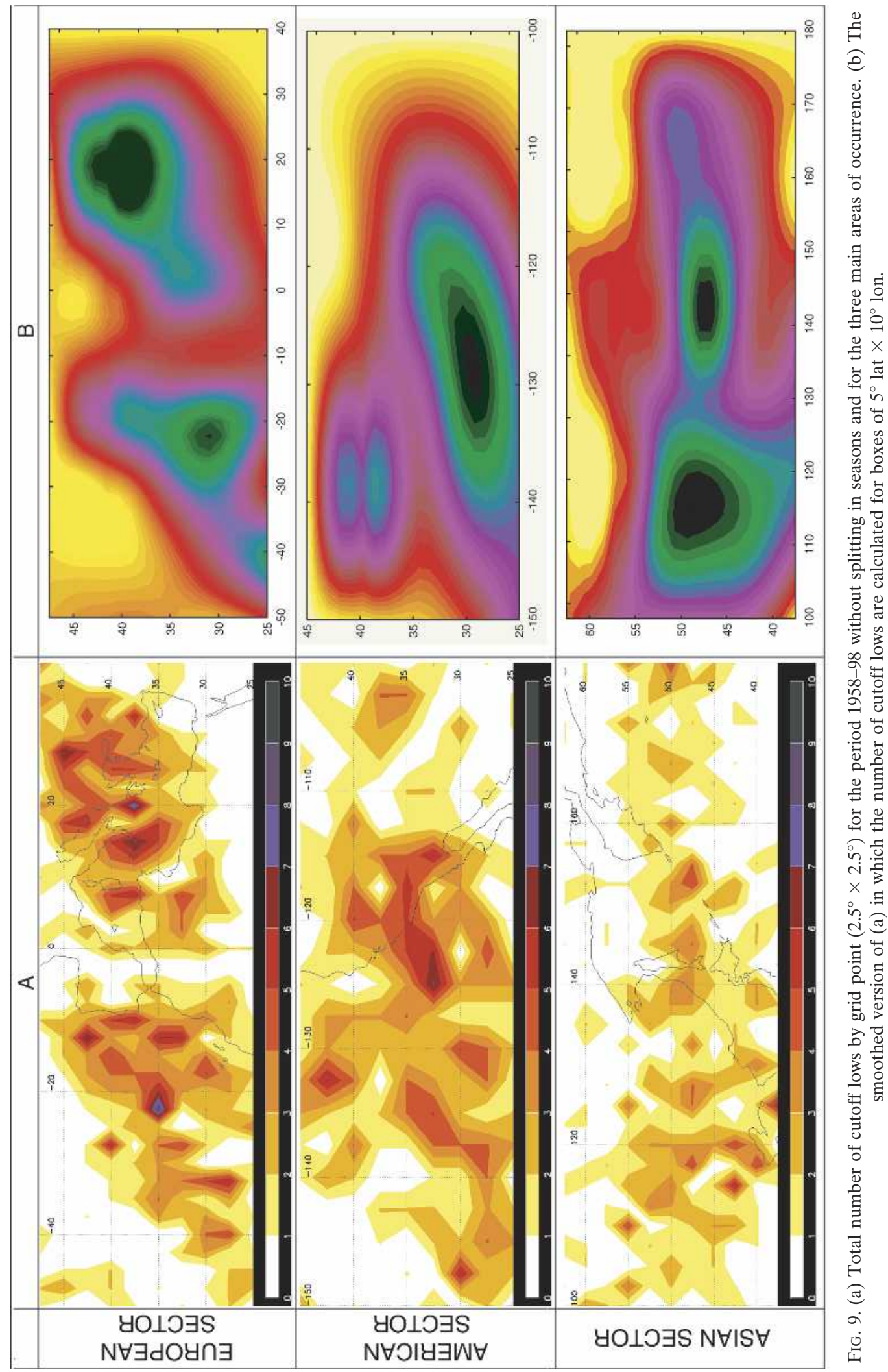




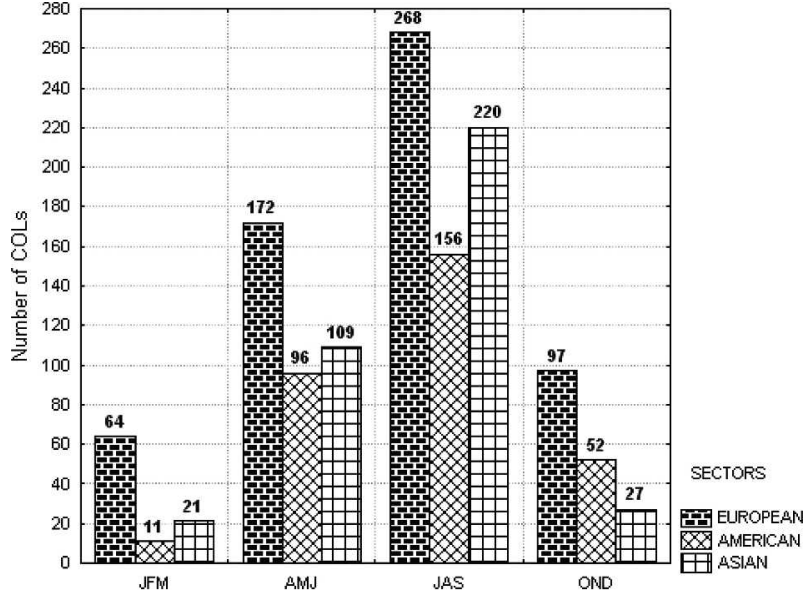

FIG. 10. Seasonal distribution of the number of cutoff lows for the three main sectors of occurrence.

to the Pacific coast during winter and it is expanded and displaced westward and to higher latitudes during spring and summer. For this season the area of occurrence is clearly located over the Pacific Ocean since the percentage of cutoff lows occurring over land are much more reduced than during spring. In fall this displacement is reversed, most of the cutoff lows being found at latitudes lower than $35^{\circ} \mathrm{N}$ and close to the American coast. A similar pattern happens in the Asian sector, so the reduced area over the Japanese coast in winter expands during spring and summer, reaching in this last season a higher extension over the continent than over the ocean.

\section{Duration and tracks}

A cutoff low system would last about a couple of days before being destroyed by diabatic heating (Hoskins et al. 1985; PV) if there were no injection of new air into the cutoff low with high potential vorticity. Most cutoff low systems have a short lifetime. In their study, KD found that the majority of cutoff lows lasted 2-3 days and very few lasted more than 10 days. In their study, $\mathrm{PV}$ found a duration range from 1 to 17 days, although most cutoff lows were short lived (74\% of cutoff lows lasted 3 days or less with $41 \%$ of them lasting only 1 day).

Figure 12 shows the number of cutoff lows lasting 2 or more days (excluding 1-day events) as a function of the duration. We can notice that most cutoff lows lasted only 2 days. So, $76.0 \%$ for the European sector, $74.3 \%$ for the American sector, and $80.3 \%$ for the Asian sector lasted only 2 days. Results also show that the number of events lasting 5 or more days is really small
$(2.3 \%, 3.5 \%$, and $1.1 \%$ for the European, American, and Asian sectors, respectively). These results confirm $\mathrm{KD}$ and PV studies in the sense of the higher frequency of short-life cutoff lows. However, our procedure of identification assigns a shorter life to cutoff lows than those used by KD and PV. This could be attributed to our way of tracking since it require contiguous cutoff low points in consecutive days to consider them as the same cutoff low. To validate this condition, we estimated, for the European sector, the percentage of cases when nonadjacent cutoff low points in consecutive days could belong to the same cutoff low. The left-hand side of Fig. 13 shows an example of two nonadjacent but close cutoff low points in consecutive days, with a relatively high probability of being the same system. But only 16 cutoff lows of a total of 601 (about 2.6\%) fulfill this condition. On the right-hand side of Fig. 13 another example is displayed, but in this case the distance between cutoff low points in consecutive days is higher, so the probability of being the same system is very reduced. There are 18 similar cases from a total of 601 . Taking into account that some of these cases are not really the same cutoff low, these percentages are even lower. So, the differences attributable to the tracking method are neglegible. On the other hand, the automated method is more restrictive that subjective methods since we do not allow a time discontinuity in the fullfillment of our conditions. This is not always the case when a subjective method is applied. In the subjective analysis, the identification of a system as a cutoff low, even if some of the conditions defining such a systems are not fulfilled, is relatively frequent. Therefore some discontinuities are inevitably included and a longer life cycle may be found. This is the reason for the small discrepancies detected in the comparison.

It has also been suggested that southern cutoff lows lasted less than northern ones, so KD found that their subtropical cutoff lows lasted between 2 and 4 days, whereas their polar cutoff lows lasted longer (most of them more than 5 days). They justified this result as a consequence of the injection of fresh polar air that produces a reintensification process in the polar type and not in the subtropical one. Figure 14 shows the contour plot of duration of our step 3 cutoff lows versus latitude and longitude. The surface was fit to the $X Y Z$ coordinate data using the bicubic spline smoothing procedure. White dots represent grid points where cutoff lows occurred and the underlined numbers on the figure denote position and duration of longer cutoff lows. In both European and American sectors longer cutoff lows also occurred in regions where cutoff lows occurred more frequently, which indicates no clear rela- 


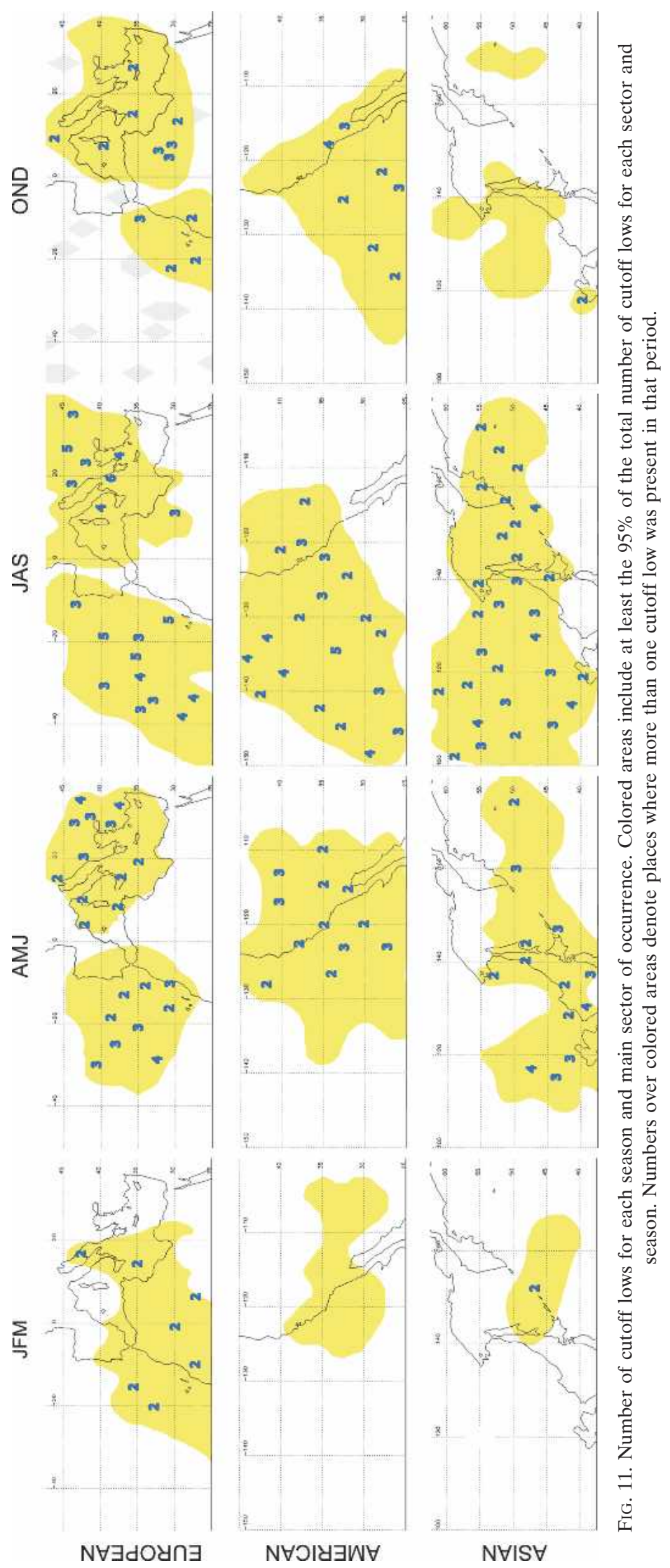




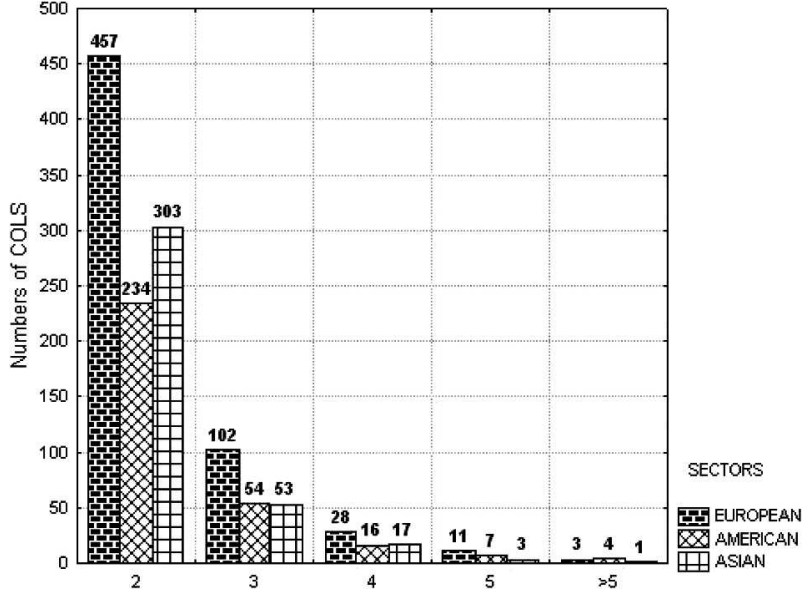

FIG. 12. Number of cutoff low events as a function of the duration for the three main sectors of occurrence.

tionship with latitude. However the area of longer duration in the Asian sector (latitude higher than $60^{\circ}$ ) is clearly different from the area of higher occurrence (latitude band between $45^{\circ}$ and $55^{\circ}$ ). This confirms KD's preliminary result that the length of cutoff lows depends on latitude only for polar cutoff lows (those placed at latitudes higher than $50^{\circ}$, an area not analyzed in the European and American sectors).

Concerning their mobility, it has been traditionally thought that cutoff lows are quasistationary. This idea comes from the work by Bell and Bosart (1989), who found that cutoff low source and dissipation areas in the Mediterranean were very close. However, in their analysis PV found that almost half of the systems moved considerably. This result was confirmed by KD, who linked duration and movement, concluding that approximately $50 \%$ of the cutoff lows that lasted more than 3 days moved considerable distances $(>600 \mathrm{~km})$. According to these authors, cutoff low motion was, as a rule, rather irregular with a trend to move northward, or northeastward, as they began to decay. A more detailed analysis appears in the study by Hernández (1999). By analyzing 271 cutoff lows over southeastern Europe, she found two kinds of behavior: those systems that were quasi stationary and those moving in a cyclonic sense with a mean gyre of $20^{\circ}$ in $12 \mathrm{~h}$ and a maximum movement of $8.75^{\circ}$ in longitude and $6.25^{\circ}$ in latitude in $12 \mathrm{~h}$. However, the author recognized that the representativeness of this result was weak due to the high variance in the movement of cutoff lows.

We have analyzed (Fig. 15) the daily displacement of the cutoff lows considering that the system is stationary (ST in the figure) if the grid point representative of the cutoff low is the same for the following day. In any other case we identified the movement by means of the positions of representative grid points (RGP), as $\mathrm{N}$ or $\mathrm{S}$ if the RGP maintains the same longitude, $\mathrm{E}$ or $\mathrm{W}$ if it maintains the same latitude, and NE, SE, SW, or NW for movement between main cardinal points. We have not considered the length of the displacement in this

\section{Long distance between COL points}

\section{Close non-adjacent points}
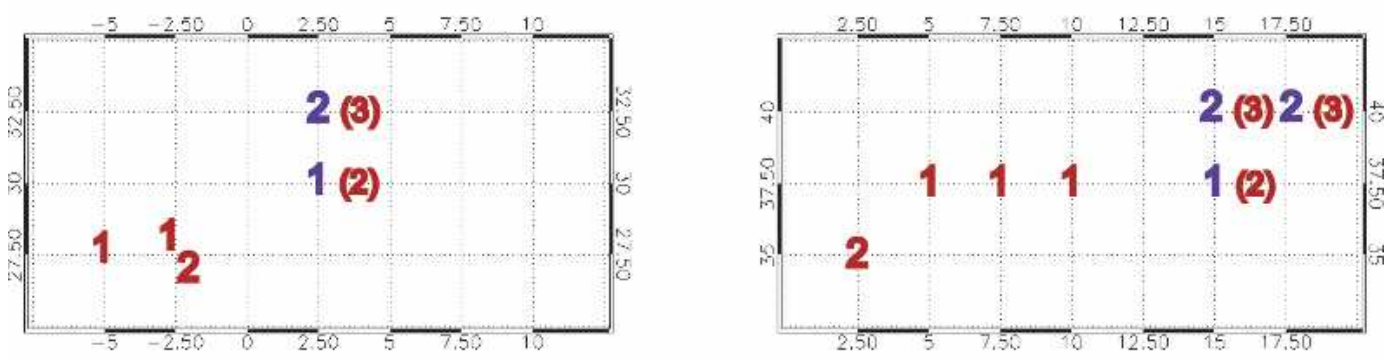

\section{A: $14 / \mathrm{march} / 1994$}

\section{B: 13/july/1996}

FIG. 13. Example of two situations where nonadjacent cutoff low points in consecutive days could belong to the same system. Case A is an example of close points, when the probability of being the same cutoff low is relatively high. In cases like B the distance between points is higher and this probability is very reduced. Cutoff low points detected as different systems by our method are displayed with different colors (the cutoff low that appears first is in red). Numbers indicate the number of day in the lifetime of the cutoff lows. Red numbers in brackets beside the blue ones show this number supposing that both cutoff lows are the same. For example, in case A our method detected two cutoff lows during 2 days. For the one in red, day 1 is 14 and day 2 is 15 Mar 1994, whereas for the blue one day 1 is 15 and day 2 is 16 Mar 1994. The day 2 point in red is very close to day 1 point in blue, so the first day point of the second cutoff low ( 1 in blue) could actually be a part of the first cutoff low in its second day ( 2 in red between brackets). 

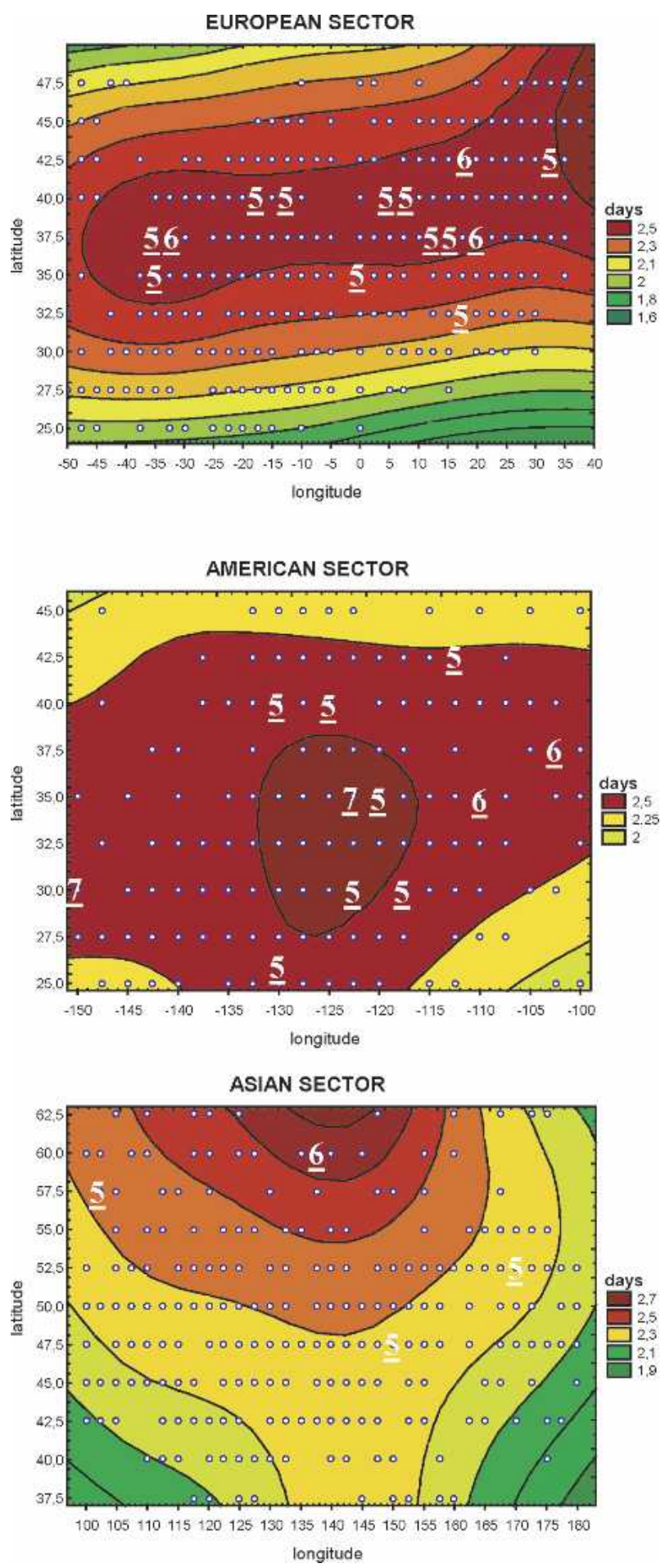

FIG. 14. Contour plot of duration of cutoff lows vs latitude and longitude (the surface was fit to the $X Y Z$ coordinate data using the bicubic spline smoothing procedure). White dots represent grid points where cutoff lows occurred and the number on the figures denote position and duration of longer cutoff lows. analysis. What the analysis accounts for is the different movement from the first day of occurrence to the second, the second to the third, the third to the fourth, and the fourth to any subsequent day. Results from this last transition - fourth to any other day-should be cautiously considered because of the reduced number of cases. Our results confirm that the number of stationary cutoff lows is lower than initially expected. Cutoff lows tend to move any time during their life cycle. So the percentage of stationary cutoff lows from the first day of occurrence to the second is $14.8 \%, 21.9 \%$, and $13 \%$ for the European, American, and Asian sectors, respectively. This percentage distribution is very similar for the second to the third day and for the third to the fourth day in the American sector where cutoff lows tend to be more stationary. The result reached by PV, that cutoff lows often moved in latitude or longitude but fewer systems moved in both latitude and longitude, was not found in our analysis as a general rule. The single transition where this happened was from the second to the third day. In this case the ratio between systems moving only in latitude or longitude versus systems moving both in latitude and longitude was 1.66, 1.23, and 1.71 for the European, American, and Asian sectors, respectively. As in PV and KD, we found considerable difficulty defining favored tracks for cutoff low systems, as their movement appeared to be rather irregular. In general, most of the systems move northward, so the ratio between movements northward $(\mathrm{N}$, $\mathrm{NW}$, and NE) and southward (S, SW, and SE) is 1.78, 1.85, and 2.48 for the first to the second day in the European, American, and Asian sectors, respectively, and similar results were reached for the second to the third day. In the transition from the third to the fourth day this preference of northward movement is not present in the American sector and it is not representative in any sector for the remaining transitions. This result contrasts with studies by PV or KD, where the northward displacement was more evident as the cutoff low started to decay. The possibly eastward displacement suggested by KD was not confirmed. In our study, European cutoff lows moved eastward in the transition from the first to the second day and westward in the rest of transitions. So, the ratio between westward movements (W, NW, and SW) and eastward movements (E, NE, and SE) is $0.59,1.30,1.73$, and 2.5 for the four studied transitions. In the American sector, cutoff lows tend to move westward in any of the transitions, so the relationship westward-eastward is $1.20,1.73,3.0$, and 3.5. In the Asian sector the westward movement is only dominant in the transitions from the second to the third day and from the third to the fourth day. 


\begin{tabular}{|c|c|c|c|}
\hline & EUROPEAN SECTOR & AMERICAN SECTOR & ASIAN SECTOR \\
\hline 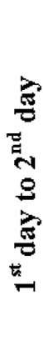 & 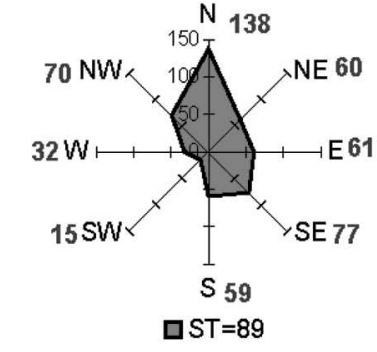 & בST=69 & 22 \\
\hline 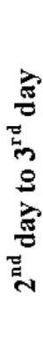 & QST=16 & 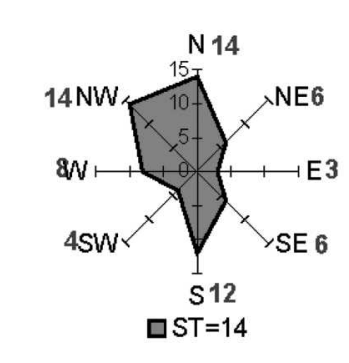 & בST=9 \\
\hline 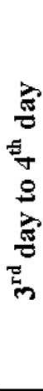 & NE44 & SWT & aST=3 \\
\hline 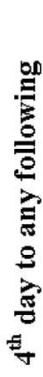 & vST=4 & & aST=0 \\
\hline
\end{tabular}

FIG. 15. Daily movement of the cutoff lows calculated as displacement of the representative grid point: ST indicates the number of stationary systems; N, NE, E, SE, S, SW, W) and NW indicates the number of cutoff lows moving toward that cardinal point. The analysis was done for four different transitions: from the first day of occurrence to the second, the second to the third, the third to the fourth, and the fourth to any other day.

\section{Conclusions}

This study provides the first multidecadal (41 yr) climatology of cutoff low systems in the Northern Hemisphere. Cutoff lows were identified using data from the NCEP-NCAR reanalysis and an objective method based on imposing the three main physical characteris- tics of the conceptual model of cutoff low. In general terms, the agreement between our objective method and the subjective procedures used in previous studies is good in extratropical areas, the method underestimates the number of cutoff lows when compared with previous studies in near-polar or polar regions and it overestimates cutoff lows for subtropical or even tropi- 
cal areas. Independent of these small disagreements, the long-term cutoff low database built is an appropriate tool to study the interannual variability of cutoff low occurrence and the links between cutoff lows and jet stream systems, blocking, or major modes of climate variability. From our study, some new interesting properties of cutoff low systems have been revealed and others previously well known have been validated.

There are three preferred areas of cutoff low occurrence: southern Europe and the eastern Atlantic coast, the eastern North Pacific, and the North China-Siberian region extending to the northwestern Pacific coast-the European area being the most favored region. This result shows that cutoff lows occur preferentially near the major troughs of the large-scale circumpolar flow. As suggested in PV and KD, the seasonal variations in latitudinal temperature gradients and temperature contrasts between continental and oceanic regions seems to be ultimately responsible for the seasonal cycle in the number and position of cutoff lows through seasonal variations in the jet system. This hypothesis can now be checked by using this long-term cutoff low database and will be one of the major objectives of a following paper. Cutoff lows form much more often in summer than in winter and at higher latitudes. About $50 \%$ of all the identified cutoff lows occurred during summer and $30 \%$ during spring, and this result is common for the three main areas of occurrence. A more exhaustive analysis of the areas of occurrence showed a bimodal distribution in Europe in all the seasons with the exception of winter, a summer displacement to the ocean in the American region, and a summer extension to the continent in the Asian region. These results are possibly related to the strength and position of the jet system during summer. Weaker jets coupled with the warmer continental areas are responsible for increasing the meridional flow in these regions of the Northern Hemisphere. Most cutoff lows lasted 2-3 days and very few lasted more than 5 days. Although with limitations, cutoff lows lasted longer when they occurred at higher latitudes. We also examined the mobility of cutoff lows. In general, most of them are mobile any day of their life cycle, with less than $20 \%$ being stationary. In most cases a northward and westward motion was evident, especially in the transitions from the second to the third day of occurrence and from the third to the fourth day.

In general, this first multidecadal and objective climatology of cutoff lows is in good agreement with previous 1-5 yr and subjective analyses, and confirms many of the known characteristics of cutoff lows, especially the main areas of occurrence and the seasonal distribution of occurrence. Other characteristics, such as the movement and duration of the systems, were only partially confirmed, finding a trend to move westward and a duration shorter than estimated in previous studies. Furthermore, the long period permitted us to define the seasonal variability for the areas of occurrence.

Acknowledgments. This work was supported by the Spanish Ministry and Science and Technology (MCYT) under Grant REN2002-04558-C04-02 and by the Galician Programme of Research and Development under Grant PGIDIT03PXIC38301PN. The authors thank three anonymous reviewers for their helpful comments and suggestions.

\section{REFERENCES}

Bamber, D. J., P. G. W. Healey, B. M. R. Jones, S. A. Penkett, A. F. Tuck, and G. Vaughan, 1984: Vertical profiles of tropospheric gases: Chemical consequences of stratospheric intrusions. Atmos. Environ., 18, 1759-1766.

Bell, G. D., and L.F. Bosart, 1989: A 15-year climatology of Northern Hemisphere $500 \mathrm{mb}$ closed cyclone and anticyclone centers. Mon. Wea. Rev., 117, 2142-2163.

Cuevas, E., and J. Rodríguez, 2002: Statistics of cutoff lows over the North Atlantic (in Spanish). Proc. Third Asamblea Hispano-Portuguesa de Geodesia y Geofísica, Valencia, Spain, Comision Española de Geodesia y Geofisica, 1-3.

- D. V. Henriques, and J. M. Sancho, 2000: Stratospheretroposphere exchange events over North Atlantic subtropical region. Proc. Second Asamblea Hispano-Portuguesa de Geodesia y Geofísica, Lagos, Portugal, Comision Española de Geodesia y Geofisica, 451-452.

García-Herrera, R., D. G. Puyol, E. H. Martín, L. G. Presa, and P. R. Rodríguez, 2001: Influence of the North Atlantic Oscillation on the Canary Islands precipitation. J. Climate, 14, 3889-3903.

Gimeno, L., E. Hernández, A. Rúa, and R. García, 1998: Surface ozone in Spain. Chemosphere, 38, 3061-3074.

Hernández, A., 1999: Un Estudio Estadístico sobre Depresiones Aisladas en Niveles Altos (DANAs) en el Sudoeste de Europa basado en Mapas Isentrópicos de Vorticidad Potencial. IV Simposio Nacional de Predicción, Instituto Nacional de Meteorología, Serie Monogr., No. SM 351, Ministerio de Medio Ambiente, 235 pp.

Hill, E. F., and K. A. Browning, 1987: Case study of a persistent mesoscale cold pool. Meteor. Mag., 116, 297-309.

Holton, J., P. Haynes, M. McIntyre, A. Douglass, R. Rood, and L. Pfister, 1995: Stratosphere-troposphere exchange. Rev. Geophys., 33, 403-439.

Hoskins, B. J., M. E. McIntyre, and A. W. Robertson, 1985: On the use and significance of isentropic potential vorticity maps. Quart. J. Roy. Meteor. Soc., 111, 877-946; Corrigendum, 113, 402-404.

Kalnay, E., and Coauthors, 1996: The NCEP/NCAR 40-Year Reanalysis Project. Bull. Amer. Meteor. Soc., 77, 437-471.

Kentarchos, A. S., and T. D. Davies, 1998: A climatology of cutoff lows at $200 \mathrm{hPa}$ in the Northern Hemisphere, 1990-1994. Int. J. Climatol., 18, 379-390.

— , G. J. Roelofs, J. Lelieveld, and E. Cuevas, 2000: On the 
origin of elevated surface ozone concentrations at Izana Observatory during the last days of March 1996: A model study. Geophys. Res. Lett., 27, 3699-3702.

Keyser, D., and M. A. Shapiro, 1986: A review of the structure and dynamics of upper level frontal zones. Mon. Wea. Rev., 114, 452-499.

Llasat, M. C., and M. Puigcerver, 1990: Cold pools over Europe. Meteor. Atmos. Phys., 42, 171-177.

Matsumoto, S. K., K. Ninomiya, R. Hasegawa, and Y. Miki, 1982: The structure and role of a subsynoptic cold vortex on the heavy precipitation. J. Meteor. Soc. Japan, 60, 339-353.

Novak, M. J., L. F. Bosart, D. Keyser, T. A. Wasula, and K. D. LaPenta, 2002: Climatology of warm season $500 \mathrm{hPa}$ cutoff cyclones and a case study diagnosis of 14-17 July 2000. Preprints, 19th Conf. on Weather Analysis and Forecasting, San Antonio, TX, Amer. Meteor. Soc., 68-71.

Oltmans, S., and Coauthors, 1996: Summer and spring ozone profiles over the North Atlantic from ozonesonde measurements. J. Geophys. Res., 101, 29 179-29 200.
Palmén, E., and C.W. Newton, 1969: Atmospheric Circulation Systems: Their Structure and Physical Interpretation. Academic Press, 603 pp.

Parker, S. S., J. T. Hawes, S. J. Colucci, and B. P. Hayden, 1989: Climatology of $500 \mathrm{mb}$ cyclones and anticyclones 1950-85. Mon. Wea. Rev., 117, 558-570.

Price, J. D., and G. Vaughan, 1992: Statistical studies of cutoff-low systems. Ann. Geophys., 10, 96-102.

— and - 1993: The potential for stratosphere-troposphere exchange in cut-off low systems. Quart. J. Roy. Meteor. Soc., 119, 343-365.

Winkler, R., and Coauthors, 2000: Manual of synoptic satellite meteorology: Conceptual models, version 5.0. [Available from Central Institute for Meteorology and Geodynamics, Hohe Warte 38, 1190 Vienna, Austria.]

Wirth, V., 1995: Diabatic heating in an axisymmetric cutoff cyclone and related stratosphere-troposphere exchange. Quart. J. Roy. Meteor. Soc., 121, 127-147. 